\title{
ARANHA, MACACO E VEADO: O LEGÍTIMO E 0 NÃO LEGÍTIMO NO ZOOLÓGICO LINGUÍSTICO NOS ESTÁDIOS DE FUTEBOL
}

\author{
SPIDER, MONKEY AND BAMBI: LEGAL AND ILLEGAL IN THE LINGUISTIC ZOO \\ OF SOCCER STADIUMS
}

ARAÑA, MONO Y MARIPOSA: LO LEGÍTIMO Y LO NO LEGÍTIMO EN EL
ZOOLÓGICO LINGÜÍSTICO EN LOS ESTADIOS DE FÚTBOL

Gustavo Andrada Bandeira*, Fernando Seffner**

\section{Palavras-chave}

Futebol.

Violência.

Racismo.
Keywords

Soccer.

Violence.

Racism.

\begin{abstract}
Resumo: As atitudes dos torcedores nos estádios produzem narrativas construídas de forma agonística. Diferentes representações de gênero, sexualidade e pertencimento étnico estão em disputas. Parece existir certa tolerância para manifestações entre torcedores quando essas acontecem através de cânticos e xingamentos. A proposta desse ensaio é problematizar como manifestações verbais se tornaram um problema a partir de quatro partidas do Grêmio em 2014. Após uma partida contra o Santos, em que 0 goleiro Aranha foi chamado de macaco por um grupo de torcedores, diferentes argumentos foram colocados para justificar ou não uma punição ao clube. Além disso, o termo "macaco", e sua derivação "macacada", historicamente autorizado para fazer referência ao Internacional, clube rival do Grêmio, foi interditado. Analisam-se quais os cânticos, xingamentos e termos foram problematizados durante essa temporada no futebol brasileiro. 0 foco da problematização se dará sobre o que foi entendido como legítimo ou não para as manifestações da torcida.
\end{abstract}

Abstract: Fans' behavior in stadiums produces agonistic narratives. Different representations of gender, sexuality and ethnic belonging are in dispute. There seems to be some tolerance toward fans' demonstrations when they happen through chanting and name-calling. This essay discusses how verbal manifestations have become a problem in four matches of Brazilian football team Grêmio in 2014. After a match against Santos, where goalkeeper Aranha (Spider) was called monkey by a group of fans, different arguments have been put forward to justify or not punishment to the club. In addition, the term "macaco" (monkey), and its derivation "macacada" (bunch of monkeys, historically used to offend the Grêmio's rival Internacional's fans) was interdicted. We analyze which chants, names and terms were debated during that season in Brazilian football. The debate will focus on what was seen as legitimate or not in fan's demonstrations.

\begin{abstract}
Resumen: Las actitudes de los hinchas en los estadios producen narrativas construidas en forma agonística. Diferentes representaciones de género, sexualidad y pertenencia étnica están en disputa. Parece existir cierta tolerancia hacia las manifestaciones entre los hinchas cuando éstas ocurren a través de cantos e insultos. El propósito de este ensayo es problematizar cómo manifestaciones verbales se han convertido en un problema partiendo de cuatro partidos del Grêmio en 2014. Después de un partido contra el Santos, donde el arquero Aranha fue llamado de mono por algunos hinchas, diferentes argumentos han sido puestos para justificar o no un castigo al club. Además, el término "mono", y su derivación "macacada", históricamente autorizados para referirse al Internacional, club rival de Grêmio, se prohibió. Analizamos qué canciones e insultos fueron problematizados durante esa temporada del fútbol brasileño. El foco de la problematización estará en lo que fue percibido como legítimo o no para las manifestaciones de la hinchada.
\end{abstract}

* Universidade Federal do Rio Grande do Sul. Porto Alegre, RS, Brasil. E-mail: gustavoabandeira@yahoo.com.br

** Universidade Federal do Rio Grande do Sul. Porto Alegre, RS, Brasil. E-mail: fernandoseffner@gmail.com

Recebido em: 10-01-2016 Aprovado em: 19-04-2016 (c) (1) () Licence 


\section{BREVES TÓPICOS SOBRE FUTEBOL E VIOLÊNCIA}

A violência, como qualquer outro artefato cultural, não é um conceito essencial, fixo ou estável. Nos estádios de futebol alguns cânticos e/ou xingamentos ${ }^{1}$ endereçados aos adversários ou às torcidas de equipes rivais poderão ser chamados de violentos enquanto outros não receberão a mesma adjetivação. Essa diferenciação não acontece apenas se examinarmos as manifestações dos torcedores em dimensão histórica, ela acontece, também, se fizermos este exame num corte apenas contemporâneo. Não há uma concordância definitiva acerca do que seja considerado violento ou não em termos de cânticos e xingamentos e este é um terreno para sempre movediço sujeito à ação de muitos atores.

No futebol, a violência² é um dos temas mais polêmicos e recorrentes, com forte expressão na mídia especializada, rendendo intermináveis debates. Se pensarmos que os estádios de futebol são um importante lugar em que se realizam construções de masculinidade, algumas violências serão permitidas, incentivadas e naturalizadas, inclusive deixando de ser consideradas violências, e sendo vistas como um exercício saudável, e no local apropriado, para expressão desses modos de masculinidade (BANDEIRA; SEFFNER, 2013; BANDEIRA, 2010; CECCHETTO, 2004; CONNELL, 1995). Para alguns, ser violento ali, no campo ou na torcida, durante aqueles 90 minutos, é algo positivo, pois extravasaria o que poderia causar problemas em outros locais, e tudo ali se esgota. Para outros, ao contrário, as atitudes violentas produzidas nos campos de futebol tendem a reforçar os comportamentos que serão transferidos para fora dos 90 minutos e do seu local apropriado, o estádio, e vão gerar violência contra outras pessoas ${ }^{3}$.

Segundo Huizinga (1993), os jogos podem ser entendidos como suspensão temporária da vida comum. Esse espaço de experimentação permite alguns deslocamentos, especialmente aos entendimentos de seriedade que produzem as ações do cotidiano. Jornalistas esportivos e alguns pesquisadores acadêmicos demarcam uma hierarquização entre o que poderia ser entendido como violência "simbólica" e violência "real"4. Para Norbert Elias (1993, p. 198), essa divisão passou a fazer sentido a partir da constituição do estado moderno e do monopólio da violência. "Formas de violência não física que sempre existiram, mas que até então sempre estiveram misturadas ou fundidas com a força física são agora separadas destas últimas. Persistem, mas de forma modificada, nas sociedades mais pacificadas". O mesmo Elias (1992) aponta que os esportes modernos estão envolvidos na tentativa constante entre manter certa tensão provocada pelos jogos e o controle da violência. É neste movediço local que este trabatho recolhe cenas para examinar.

A proposta deste ensaio é problematizar como manifestações verbais se constituíram enquanto um problema a partir de quatro partidas do Grêmio ${ }^{5}$ em 2014. As fontes são a cober-

\footnotetext{
1 É uma tarefa bastante complicada conseguir distinguir o que é cântico do que é xingamento neste contexto. Essa ambiguidade decorre, em grande medida, da forma como os diferentes atores interagem com o ambiente em que esses são produzidos e qual o lugar entre profanadores ou profanados os diferentes sujeitos se encontrem.

2 Algumas interpretações apontam como a própria linguagem bélica do futebol permitiria, inclusive, fazer com que o esporte fosse entendido como um substituto para os impulsos direcionados ao conflito armado (BRANCO, 2006).

3 É relevante destacar, também, como a violência pode ser criada por marcadores daquele espaço. Torcedores poderão utilizar a violência para a disputa de honras masculinas (MOREIRA, 2013) e, mesmo, organizar a sociabilidade entre eles (ALABARCES, 2012). A violência, também, pode permitir que o protagonismo das ações nos estádios de futebol seja disputado para além das quatro linhas do campo de jogo (RIBEIRO, 2007). 4 Conceitualmente, essa separação poderia lida da seguinte maneira: "a violência real, que é perceptível pelas agressões físicas de contato, enquanto a violência simbólica é visível pelas agressões verbais e/ou gestuais" (REIS, 2005: p. 114). 
tura midiática ${ }^{6}$ e a presença no estádio em três ${ }^{7}$ dessas quatro partidas. 0 texto tem forte estrutura narrativa, alinhando possíveis conclusões a cada momento ou partida. Analisam-se quais os cânticos, xingamentos e termos foram problematizados durante essa temporada no futebol brasileiro e não se pretende chegar a nenhuma conclusão estável, pois assumimos tanto que o terreno é movediço quanto que as modificações introduzidas no ano de 2014, em que se realizou a segunda Copa do Mundo de futebol masculino da Federátion Internationale de Football Association (FIFA) no Brasil, no futebol brasileiro ainda estão longe de esgotar seus efeitos, dentre os quais um deles é o que analisamos aqui, a pertinência ou não de certos cânticos ou xingamentos durante os jogos. As partidas em questão são: Grêmio 0 X 2 Santos, Grêmio $1 X$ 0 Bahia, Grêmio 0 X 0 Santos e Grêmio 4 X 1 Internacional. O foco da problematização se dará sobre 0 que foi entendido como legítimo e o que foi interdito para as manifestações coletivas da torcida. Como questões de raça, gênero e sexualidade experimentam diferenças no que é tido como legítimo ou não durante os jogos de futebol dentro dos estádios?

\section{GRÊMIO 0 X 2 SANTOS, COPA DO BRASIL}

Em 28 de agosto, Grêmio e Santos fizeram a primeira partida das oitavas de final da Copa do Brasil de 2014 na Arena do Grêmio, em Porto Alegre. Apesar do ímpeto inicial, a equipe gaúcha acabou sofrendo dois gols na parte final do primeiro tempo em falhas da defesa. No segundo tempo, os gaúchos se jogaram ao ataque, mas sem êxito, pecando nas conclusões ou parando em uma atuação segura do goleiro Aranha.

Infelizmente, não foram os predicados técnicos do goleiro Aranha que o tornaram protagonista de uma das partidas mais discutidas no futebol brasileiro em 2014. Próximo ao final da partida, o goleiro da equipe paulista afirmou que torcedores do Grêmio posicionados na Arquibancada Inferior Norte (setor com ingressos mais baratos e que é destinado aos torcedores que assistem às partidas em pé e às torcidas organizadas) o chamaram de "preto fedido" e "macaco", além de fazerem sons de macaco em direção ao atleta. Ao final da partida o goleiro se manifestou: "Fiquei bem nervoso. Com o perdão da palavra, fiquei p... Isso dói. Não é possível. Me chamaram de preto, de macaco. Bati no braço e disse que sou preto mesmo"."

Na madrugada do dia 29 de agosto, o Grêmio emitiu nota solidarizando-se com o goleiro santista:

O Grêmio Foot-Ball Porto Alegrense lamenta e repudia 0 ato de racismo ocorrido na noite desta quinta-feira, durante partida realizada pela Copa do Brasil, na Arena do Grêmio. O Clube se solidariza com o atleta Aranha e com seu clube, Santos, ressaltando que atos como esse são fruto de atitudes individuais e isoladas, que em nada representam a grandiosidade e o respeito da torcida gremista. [...]. Reiteramos que o Grêmio tem sido um incentivador de iniciativas que visam coibir esse tipo de crime e que continuará alerta e atuante na luta contra a discriminação racial $^{10}$

\footnotetext{
6 A cobertura ficou restrita aos portais esportivos da internet. Para a escrita final deste texto, as reportagens utilizadas foram buscadas nos sítios: www.globoesporte.com, www.zh.clicrbs.com.br e www.correioropovo.com.br. Para as discussões sobre a importância do jornalismo esportivo, ver entre outros MARQUES, 2014; DAMO, 2006; HELAL, 2006.

7 Não estivemos presentes ao primeiro jogo da série analisada, Grêmio 0 X 2 Santos.

8 Minimamente é possível verificar como a própria imprensa esportiva participa deste jogo de disputas por significados. A expressão puto é interditada, enquanto em outras oportunidades é possível ler veado e, especialmente, macaco, principal termo envolvido na disputa por manifestação legítima ou ilegítima nos estádios de futebol.
}

9 ARANHA..., 2014.

10 GRÊMIO..., 2014b. 
O assessor de futebol do clube gaúcho, Marcos Chitolina, defendeu punição aos torcedores ao mesmo tempo em que procurou eximir o clube: "Não vamos compactuar com o racismo, mas 0 Grêmio não pode ser punido por um ato individual ${ }^{11 "}$. 0 argumento de defesa do clube e responsabilização individual dos diretamente envolvidos pode ser pensado exclusivamente como uma tentativa de produzir ganho jurídico. Porém, é possível inserir essa argumentação em certo viés moral. "Partimos del hecho de que nadie acepta ser definido como violento dada la ilegitimidad de ese rótulo, entonces la clasificación de sujetos y acciones como violentas estigmatiza y funciona como forma de control social" (GARRIGA ZUCAL, 2010, p. 29). Nesse marco moral é necessário destacar desde o início que os violentos são os outros ou, no mínimo, isolar os protagonistas dos atos. Uma imagem produzida pelo canal de televisão ESPN flagrou a torcedora Patrícia Moreira gritando o termo "macaco". Essa torcedora acabou sendo colocada como a principal responsável pelas ofensas dirigidas ao goleiro. Ela passou a ser ameaçada e teve que deixar sua residência, que chegou a ser alvo de pedradas, após a divulgação das imagens. A imagem da jovem e loira torcedora ${ }^{12}$ conseguiu personificar a injúria racial e acabou servindo como argumento para que o clube apresentasse a hipótese de que a ofensa se tratava de uma ação isolada.

Como em qualquer contexto cultural, algumas violências parecem ser mais violentas que outras. "O aspecto social da conceituação de violência refere-se a que, em um grupo social, alguns vão nomear como violência algo que outros poderão considerar como corriqueiro ou não violento, isso na dependência de fatores culturais" (SEFFNER, 2004, p. 89). Por vezes a violência que não inclui enfrentamentos corporais acaba sendo naturalizada, especialmente em contextos de multidões como os estádios de futebol.

Dentro dessa lógica de naturalização ou de dificuldade de perceber os xingamentos como uma agressão ou como violência, o árbitro da partida, Wilton Pereira Sampaio, ao ser informado sobre o que estava ocorrendo, por jogadores da equipe paulista e por um dos árbitros auxiliares, fez uma reprimenda ao goleiro Aranha por este ter, supostamente, provocado a torcida batendo nos braços, em um gesto que ficou relacionado no futebol a uma demonstração de garra realizada pelos atletas e, eventualmente, por torcedores.

Em um primeiro momento, o árbitro não fez constar em sua súmula o episódio de xingamentos dirigidos ao goleiro santista. Ele acabou fazendo um adendo à súmula e a encaminhou ao procurador do Superior Tribunal de Justiça Desportiva (STJD) Paulo Schmidt, relatando o fato. 0 procurador do STJD, ao receber o adendo do árbitro, afirmou ter feito a solicitação das imagens. Ele afirmava que o Grêmio poderia ser enquadrado no artigo 243-G do Código Brasileiro de Justiça Desportiva por "praticar ato discriminatório, desdenhoso ou ultrajante, relacionado a preconceito em razão de origem étnica, raça, sexo, cor, idade, condição de pessoa idosa ou portadora de deficiência ${ }^{13 "}$.

\section{GRÊMIO 1 X 0 BAHIA, CAMPEONATO BRASILEIRO}

No domingo seguinte, dia 31 de agosto de 2014, o Grêmio retornou à Arena para enfrentar o Bahia pela 18ª rodada do Campeonato Brasileiro da Série A. O jogo, tecnicamente

12 Não está entre os objetivos deste ensaio uma análise da torcedora em questão. Entretanto, seria possível imaginar que no caso de o flagrante televisivo ter sido feito em outro torcedor com marcadores fenotípicos e de gênero distintos, a repercussão poderia ter sido diferente. 13 ÁRBITRO..., 2014. 
muito ruim, terminou com vitória gaúcha com um solitário gol do argentino Barcos. Os jogadores do Grêmio entraram em campo com uma faixa com os dizeres "Somos azuis, pretos e brancos. Chega de racismo". Em diferentes setores do estádio, cartazes de torcedores faziam coro à afirmação: "O Grêmio não é racista"; "Gremista sim, racista não. Não generalizem"; "Diga não ao racismo!!"; "\#Somostodosgremistas. Não somos todos racistas. Punição para aqueles que não nos representam. Somos azuis pretos e brancos 14".

Ainda com a polêmica surgida a partir do caso Aranha, o comportamento de diferentes segmentos da torcida apresentou uma situação inédita no novo estádio. Se buscássemos a série histórica dos jogos no estádio Olímpico Monumental ${ }^{15}$, o ineditismo do comportamento dos torcedores se manteria. A torcida Geral do Grêmio (principal ocupante do setor Arquibancada Inferior Norte, de onde partiram as ofensas ao goleiro santista) cantou a maioria de seus cânticos da mesma forma que fazia, inclusive durante a partida contra o Santos, pela Copa do Brasil, com o termo "macaco" e sua derivação "macacada" para referir-se ao coletivo de torcedores do Internacional ${ }^{16}$. Essas manifestações através dos cânticos poderiam estar ancoradas em sua permissividade histórica. "Nos estádios [...] são permitidas certas manifestações que ordinariamente não seriam toleradas, pois, assim como o templo é o lugar da prece, o estádio é a tribuna dos insultos". ${ }^{17}$ Ao contrário do recorrente apoio ou da adesão de torcedores de distintos segmentos aos cânticos, as manifestações vindas da Geral foram recebidas com vaias por uma parte significativa do restante do público.

O presidente do Grêmio, Fábio Koff, bradou contra as manifestações, lidas por ele como racistas, e prometeu a exclusão dos envolvidos, além de questionar os interesses dos sujeitos:

Eu tenho a lamentar de novo os cânticos racistas que não cabem dentro do estádio. Não há como o Grêmio admitir isso como instituição. Nós temos que enfrentar o problema e com muito rigor. Pois estamos sofrendo consequências... Estamos a dois dias de um julgamento que pode excluir o Grêmio de uma competição e parece que propositalmente querem prejudicar o Grêmio. Que torcedor é esse que vai ao estádio para prejudicar o seu clube? ${ }^{18}$

Como o Grêmio seria julgado pelos incidentes da partida anterior, a direção tricolor suspendeu a torcida Geral do Grêmio e admitiu, talvez pela primeira vez na história, que considerava os termos "macaco" e "macacada", repetidamente cantados no estádio gremista, como uma manifestação racista. Ao longo dos anos esses cânticos sempre foram questionados quando casos de racismo eclodiam no futebol. Nos demais momentos "ordinários" esses cânticos não eram noticiados ou apontados como violentos, o que, em alguma medida, mostra como esse termo (ou essa violência) estava naturalizado no contexto dos torcedores de futebol. Apesar das discussões ocasionais, os cânticos se mantiveram inalterados até aquele momento.

O caso Aranha foi o segundo caso de racismo ocorrido na Arena do Grêmio em um intervalo de cinco meses. Após a primeira partida da final do Campeonato Gaúcho de 2014, 0 zagueiro Paulão, do Internacional, foi chamado de macaco por um torcedor do Grêmio. $\mathrm{O}$ caso

\footnotetext{
14 GRÊMIO..., 2014c.

15 Estádio em que o Grêmio atuou como mandante entre 1954 e 2013.

16 As torcidas de Grêmio e Internacional cumprem o mesmo ritual de xingar os torcedores rivais da dupla Gre-Nal, mesmo quando os confrontos não incluem os dois adversários históricos.

17 DAMO, Arlei Sander. Futebol, engajamento e emoção. In: ESPORTE e mídia: novas perspectivas: a influência da obra de Hans Ulrich Gumbrecht. Rio de Janeiro: EdUERJ, 2014a. p.1 -28. p. 25.[no prelo]

18 KOFF..., 2014.
} 
envolvendo o defensor colorado acarretou uma multa de $\mathrm{R} \$ 80$ mil ao clube. 0 torcedor que ofendeu o jogador não foi identificado. Ainda em 2013, o departamento de marketing do clube lançou a campanha "Azul, Preto e Branco: o Grêmio é contra o racismo". Essa preocupação em desvincular o Grêmio de sua representação racista tem atravessado a instituição nos últimos anos. Os cânticos da torcida Geral do Grêmio sempre estiveram no centro das discussões ${ }^{19}$. Já no momento da agressão ao zagueiro do Internacional, um grupo de torcedores propôs, sem êxito, que o termo "macaco" fosse excluído das arquibancadas e cadeiras da Arena²0.

Contrariando a opinião do então mandatário gremista, o ex-presidente do Grêmio e atual integrante de um programa de rádio, Luis Carlos Silveira Martins apontou o "folclore do futebol" para explicar e minimizar os eventos envolvendo o goleiro santista ou os cânticos com o termo "macaco". Édison Gastaldo faz uma interessante ressalva sobre essa marcação,

[...] à primeira vista, trata-se apenas de futebol, mas o sistema de valores que fundamenta as interações é basicamente o enquadramento moral da sociedade como um todo, com sua demanda pela defesa da honra, da dignidade e da autonomia, atributos bastante vinculados à identidade de gênero masculino no Brasil (GASTALDO, 2010, p. 313).

O ex-dirigente utilizou a rivalidade do Grêmio com o Internacional para reforçar seus argumentos:

Dentro do folclore do futebol, o Internacional coloca uma faixa 'aqui é macacada'. É dentro do folclore do futebol. Se você passar pela rua, encontrar um negrão, um afrodescendente e dizer 'olha, negro macaco', você está praticando um racismo grosso, sim. Mas nesse contexto do futebol, nessa forma, é o fim do futebol ${ }^{21}$.

O comunicador ainda utilizou outra estratégia, a de desqualificar ou culpabilizar a vítima para seguir argumentando de forma contrária à reação do goleiro em relação à agressão sofrida:

Vai investigar o passado do Aranha em broncas para ver o que tem. Desse santinho, desse coitadinho que ele é. Vamos investigar o passado, que eu fui investigar. Há transgressões e transgressões. Algumas são simplesmente aceitas. Se fosse por isso, vou fazer uma gradação de transgressões. O Aranha não deixou o jogo andar. Interrompeu o jogo o tempo inteiro. Infringiu a lei o tempo inteiro. Aí ouviu um gritinho, coitadinho, que tem um passado de broncas parecidas, foi lá e fez aquela cena teatral22.

Nesse caso o comportamento do jogador poderia ser entendido como um incentivador aos xingamentos ou um atenuante para a prática racista. Além da opinião do ex-presidente do clube, o então vice-presidente, Adalberto Preis também se manifestou criticando o goleiro Aranha por meio da rede social Twitter. $O$ dirigente lembrou que o goleiro retardou a partida e utilizou manifestações do árbitro da partida que teria dito não ter visto as manifestações, mas que havia sido avisado pelos atletas. 0 vice-presidente foi categórico: "Sabem por que o árbitro não ouviu nem presenciou? Porque não houve. Foi tudo uma grande encenação do goleiro para fazer cera ${ }^{23 "}$. Ao contrário do clube, que emitiu comunicado oficial pedindo desculpas ao goleiro e ao clube adversário pelo episódio, o vice-presidente reforçou que nada havia acontecido durante a partida entre Grêmio e Santos. 
Ao mesmo tempo em que manifestações como essas parecem pedir certa tolerância ao que foi praticado pela torcida, seus autores não conseguem separar facilmente 0 que seria do jogo e o que não. A defesa da agressão ou igualar a agressão racista, ao menos conceitualmente exógena ao futebol, com o retardo da reposição de bola pelo jogador santista ajuda a borrar o que seria a esfera séria da vida ordinária com o tempo extraordinário do esporte, do lazer, do jogo.

\section{STJD X GRÊMIO, JULGAMENTO}

Além da campanha institucional e da adesão de torcedores ocorridas na partida contra o Bahia, o departamento jurídico do Grêmio estava envolvido na tentativa de preparar a defesa do clube, que seria julgado, uma semana após a partida, sobre os incidentes ocorridos na Copa do Brasil. O jogo de volta já havia sido suspenso preventivamente e o clube ainda poderia ser excluído da competição ou perder dez mandos de campo em jogos do Campeonato Brasileiro.

Em julgamento no dia 3 de setembro de 2014, o Grêmio acabou excluído da Copa do Brasil, além de ter sido multado em $\mathrm{R} \$ 54$ mil $(\mathrm{R} \$ 50$ mil referentes ao caso de injúria racial, $\mathrm{R} \$ 2$ mil por um rolo de papel higiênico arremessado em direção ao gramado e outros $R \$ 2$ mil por atraso da equipe ao entrar em campo). 0 presidente da FIFA, à época, elogiou o comportamento do STJD na punição aplicada ao clube gaúcho. Pela rede social Twitter, Joseph Blatter posicionou-se: "Eu já disse que o futebol deve ser mais forte no combate ao racismo. O Brasil enviou a mensagem certa, banindo uma equipe da Copa devido a abuso de 'torcedores'24".

Após a condenação, a torcida Geral do Grêmio baniu o termo "macaco" de seus cânticos. Os cânticos foram citados durante o julgamento do clube no STJD. No vídeo em que divulgou a suspensão do termo, a torcida afirmava que ele não tinha caráter racista. A suspensão se daria "por tempo indeterminado, até que seja esclarecido que cantar a palavra dentro do contexto do folclore do futebol não é um ato racista ${ }^{25 "}$ ". Aqui a disputa pela legitimidade ou não do termo "macaco" evidencia o campo de disputas culturais em que essas definições se colocam.

Dado que las nociones de violencia pueden no ser uniformes ni siquiera dentro de una misma cultura, la legitimidad es un elemento crucial en lo que se reconoce 0 no como violencia. Hay que rastrear en la legitimidad de los actos para ver qué se define como violencia. Aquí es necesario pensar las tensiones que existen entre distintas legitimidades, entendiendo que muchas veces lo legítimo para una mayoría no lo es para todos (GARRIGA ZUCAL, 2010, p. 29).

Novamente 0 apelo ao folclore do futebol permite o estabelecimento de um diálogo do que seria vida "real" e vida "folclórica", cada uma em seu tempo e espaço definidos, onde "o jogo [ou o folclore] é essencialmente uma ocupação separada, cuidadosamente isolada do resto da existência, e realizada, em geral, dentro de limites precisos de tempo e de lugar" (CAILLOIS, 1990, p. 26). A partir dessa data, e até o final da temporada de 2014, o termo que era autorizado historicamente na Arena do Grêmio e, muito antes, no estádio Olímpico estava interditado. Daquele dia em diante não se ouviu mais "macaco" ou "macacada" na Arena do Grêmio ${ }^{26}$.

\section{PRESIDENTE..., 2014.}

25 GERAL..., 2014.

26 Na temporada de 2015 se mantém a prudência em relação ao termo "macaco" e seu derivado "macacada". No estádio, é possível escutar alguns cânticos que contêm as expressões "macaco puto segue sempre imitando" ou "macacada filha da puta". Entretanto, a incidência dessas manifestações é bastante menor em relação ao que acontecia antes do episódio com o goleiro Aranha. 
O pleno do STJD acabou alterando a decisão em segunda instância, em julgamento ocorrido no dia 26 de setembro. Ao invés de excluir o clube gaúcho da competição, os auditores puniram o clube com a perda de pontos, o que, somado à derrota na primeira partida, cumpriu o mesmo efeito prático de eliminar o Grêmio da competição. O procurador do STJD, Paulo Schmitt argumentou que o clube precisaria ser responsabilizado pelos atos de seus torcedores. Segundo ele:

[...] não se separa o clube e a torcida. Quem separa tenta desinformar a sociedade. Clube e torcida é uma coisa só. Quando o clube teve uma nova oportunidade, vaiou o goleiro, quando ele deveria ser aplaudido pela coragem, por trazer à tona o que a gente esconde debaixo do tapete ${ }^{27}$.

É um tanto curioso que essa discussão entre a responsabilidade do clube e da torcida ou de torcedores individuais pareça se dar mais em relação ao peso da punição do que ao que de fato ocorreu. $O$ Grêmio não recorreu da pena de $R \$ 80$ mil imposta após o caso de racismo envolvendo o zagueiro Paulão, do Internacional. Em 2014, o Grêmio precisou disputar uma partida do Campeonato Gaúcho em Novo Hamburgo, cidade da Região Metropolitana de Porto Alegre, em função de um sinalizador lançado por um torcedor em uma partida realizada em Caxias do Sul. Se o clube pode ser responsabilizado e multado em $\mathrm{R} \$ 2$ mil porque um torcedor arremessou um rolo de papel higiênico para dentro do gramado, por que o clube não teria responsabilidades por manifestações racistas? Seria o caso de investigar se para situações de punições pecuniárias os clubes buscam indenização junto aos autores das ações que produziram as eventuais multas ou se as pagam dentro do "risco do negócio" ou por se perceberem responsáveis por tais condutas.

\section{GRÊMIO 0 X 0 SANTOS, CAMPEONATO BRASILEIRO}

Os jogos de futebol estão sempre inseridos em calendários e competições que ampliam a significação de um jogo específico (DAMO, 2014). Qualquer jogo se dá dentro de uma série histórica e envolve repetições e diferenças nos códigos culturais. Grêmio e Santos voltaram a se enfrentar na Arena do Grêmio no dia 18 de setembro de 2014 pelo Campeonato Brasileiro. Foi um reencontro entre os clubes, o goleiro Aranha e o estádio em que os gritos racistas aconteceram em um intervalo de três semanas e quinze dias após a exclusão do Grêmio da Copa do Brasil. O jogo teve um número pequeno de oportunidades de gols. Novamente os gaúchos tiveram um pequeno domínio, mas foram incompetentes nas conclusões. Além das manifestações da torcida, o goleiro Aranha também teve destaque pela qualidade de sua atuação.

O goleiro foi alvo de ironias e protestos por parte dos torcedores do Grêmio, incluindo aplausos quando o jogador retinha a bola até gritos como "vai, Branca de Neve" ou termos que desqualificavam as virtudes técnicas do jogador como "mão de alface" e "frangueiro". O goleiro também foi muito vaiado desde o aquecimento e após praticar suas defesas. 0 grito "Aranha, veado" foi escutado durante toda a partida. A dimensão das vaias e os gritos de "veado" fizeram o goleiro lamentar a postura dos torcedores: "Eu, sinceramente, esperava ser recebido de outra maneira. Acreditava que a grande maioria tinha repudiado as atitudes. Pelo que vi hoje, concordam com tudo. Acham isso bonito. Eles seguem a vida deles, e eu a minha28". O goleiro santista entendeu que, pelo comportamento da torcida na partida, o coletivo de torcedores do Grêmio concordava com as agressões sofridas por ele na partida anterior: 
Fiquei triste porque deu para perceber bem qual é o pensamento do torcedor gremista, da grande maioria que apoiou o ato. [...] Eu não ligo para as vaias, para manifestação do torcedor, desde que seja do esporte. E a gente, sem ser hipócrita, sabe que a vaia hoje foi diferente ${ }^{29}$.

O goleiro argumentou, também, que seria comum atletas negros sofrerem ofensas racistas quando enfrentam o Grêmio:

Isso serve para mudar o pensamento das pessoas, porque tem gente que só meIhora com medo. Muita gente não me xingou hoje com insultos racistas porque sabia que estava sendo filmada. Mas a intenção era a mesma. Eu vi isso hoje. [...] Já há muitos anos isso acontece, é uma briga interna aqui. Todo mundo sabe, mas não fala. Vai deixando, empurrando, até quando der ${ }^{30}$.

Na partida aqui em análise duas outras situações foram notáveis. Com a proibição do termo "macaco", a torcida do Grêmio não fez referência ao Internacional, seu rival histórico. Os cânticos eram todos de incentivo ao time e não ofendendo o rival, como costumeiramente ocorria. A segunda situação que destacamos ocorreu após a partida. As rádios locais elogiaram 0 comportamento das torcidas, que, segundo elas, pressionaram, mas não ofenderam o goleiro. O zagueiro Rhodolfo, do Grêmio, entendia que a reação da torcida foi normal durante a partida: "Cheguei na hora que ele levou pancada e falei para ele que não precisava reclamar. É normal a torcida vaiar, xingar. Acho que dessa vez não teve racismo, graças a Deus não aconteceu isso ${ }^{31 "}$.

A opinião do jornalista Hiltor Mombach foi bastante interessante. Segundo ele, os torcedores que gritaram "Aranha, veado" corroboraram os insultos racistas. Ele argumentou que o termo "veado" afirmava o insulto protegido pela impunidade ${ }^{32}$. Dois desdobramentos dessa avaliação merecem destaque. A ofensa dirigida ao goleiro nessa segunda partida, no caso 0 termo "veado", foi interpretada como uma ofensa racista e não ligada ao uso sexual ao qual o termo é costumeiramente associado no Brasil. $O$ segundo desdobramento se refere à impunidade. Ao pensar que os dois termos, "macaco" e "veado", são racistas, por que somente um dos termos estaria autorizado? Mais uma vez nos defrontamos com esta fronteira movediça entre o permitido e o proibido. Ao reforçar o combate, as ofensas racistas se voltam a naturalizar os xingamentos relacionados às sexualidades desviantes, além de corroborar sua permissividade.

As atitudes dos torcedores nos estádios de futebol produzem uma narrativa. Essa narrativa é construída de forma agonística na relação entre nós e eles. Não são apenas as partidas que estão em disputa, mas diferentes representações, dentre elas as regionais e de gênero, especialmente vinculadas às construções de masculinidades. Sendo o estádio de futebol um campo de construções da masculinidade, o "enfrentamento" ao outro homossexual acaba sendo naturalizado. No futebol as masculinidades são dramatizadas, mas, no futebol brasileiro, o pertencimento étnico acabou sendo posto de lado. Algumas narrativas, inclusive, destacam como o futebol foi e é protagonista na construção de uma "democracia racial" no Brasil. Além disso, o combate ao termo "macaco" tem uma referência histórica mais permanente. Poderia se apontar que a primeira discussão sobre o termo apareceu no longínquo torneio Sul-Americano de $1919^{33}$.

\footnotetext{
29 CREPALDI, 2014.

30 GRÊMIO..., 2014C.

31 MENEZES, 2014.

32 MOMBACH, 2014.

33 Ver PEREIRA, 2014.
} 


\section{GRÊMIO 4 X 1 INTERNACIONAL, CAMPEONATO BRASILEIRO}

Neste recorte histórico que estabelecemos não há muito espaço para conclusões estáveis. Só podemos pensar avançando mais um tempo na série histórica. Seguimos, ainda, cheios de indagações, mas com caminhos para continuar a pesquisa. Para encerrar esta série histórica, vamos à participação da torcida gremista no Gre-Nal da Arena pelo Campeonato Brasileiro, em 9 de novembro. Certamente a atuação daquela partida foi a mais qualificada do Grêmio na temporada de 2014. Com grande velocidade, a equipe gremista suplantou seu maior rival, com destaque para o argentino Alan Ruiz, que atuou por 12 minutos e marcou dois gols.

Uma vez que os termos "macaco" ou "macacada" não poderiam ser utilizados para se referir aos torcedores do Internacional, o histórico rival vinha sendo menos xingado nas partidas pós "caso Aranha". A despeito disso, antes do jogo tínhamos como hipótese que a torcida gremista ignoraria as interdições e voltaria a xingar o rival histórico e, com isso, retomaria os termos "macaco" e "macacada" no âmbito do estádio. Pensávamos isso baseados na força da tradição histórica, aqui perturbada pelos fatos narrados no recorte proposto. Nossa percepção se mostrou equivocada. Dentro do estádio, os cânticos gremistas foram os de exaltação ao clube, sem mencionar o rival. Somente no segundo tempo a torcida gremista conseguiu se referir aos adversários como "putos do Inter", dentro da lógica de que o "puto" estaria no mesmo registro do "veado", ou seja, não "ofensivo" ou não passível de punição. Essa distinção não é exclusiva dos estádios de futebol. A partir do que podemos entender como circuito da cultura, essa oposição já aparece em outras esferas de nosso cotidiano, incluindo o humor e, mesmo, políticas públicas específicas. Em relação a eventuais sanções, questões de raça/etnia já experimentam criminalização no Brasil, enquanto questões de sexualidade não.

Fora do estádio, porém, após vencer o rival depois de dois anos, os termos "macaco" e "macacada" retornaram como se nada tivesse acontecido. Todos os cânticos interditados após a condenação do clube na Copa do Brasil foram trazidos de volta. Nenhum desses cânticos de fora do estádio apareceu nas falas de jornalistas, dirigentes ou atletas. A restrição ao comportamento dos torcedores e aos seus cânticos parece que se aplica/aplicou somente dos portões do estádio para dentro em um processo não muito diferente do que ocorreu com enfrentamentos físicos, que nos últimos anos se deslocaram do estádio e de seus arredores imediatos para estações de trens ou outros espaços das cidades, "desresponsabilizando", de certa forma, clubes e torcidas.

Se a luta antirracismo é uma demanda absolutamente justa, assim como outras que poderão aparecer, e parece estar ganhando força nos estádios de futebol, é necessário não desvinculá-la do processo de gentrificação dos estádios ${ }^{34}$. Mesmo enxergando movimentações dos clubes apenas vinculadas aos riscos de punição desportiva e referentes a termos e lugares muito específicos - e sendo absolutamente favoráveis às pautas dos direitos humanos - pensamos que é necessário problematizar ou questionar se esses conteúdos não estão aparecendo junto com a elitização do público e a restrição de comportamentos mais associados ao popular nas praças esportivas brasileiras. Seguimos acompanhando a série histórica, para ver seus desdobramentos. A partida está longe do final!

34 Ver Hollanda, 2014. 


\section{REFERÊNCIAS}

ALABARCES, Pablo. Crónicas del aguante: fútbol, violencia y política. Buenos Aires: Capital Intelectual, 2012.

ARANHA protesta contra ato de racismo na Arena: "Dói." 28 ago. 2014. Disponível em: <http:// zh.clicrbs.com.br/rs/esportes/gremio/noticia/2014/08/aranha-protesta-contra-ato-de-racismo-na-arenadoi-4585928.html>. Acesso em: 2 jan. 2015.

ÁRBITRO inclui na súmula de Grêmio x Santos caso de racismo na Arena: Paulo Schmitt, procurador do Tribunal, confirmou que o STJD já solicitou imagens das arquibancadas. 29 ago. 2014. Disponível em: <http://zh.clicrbs.com.br/rs/esportes/gremio/noticia/2014/08/arbitro-inclui-na-sumula-de-gremio-xsantos-caso-de-racismo-na-arena-4586196.html>. Acesso em: 1 jan. 2015,

BANDEIRA, Gustavo Andrada. Um currículo de masculinidades nos estádios de futebol. Revista Brasileira de Educação, v. 15, n. 44, p. 342-51, maio/ago. 2010.

BANDEIRA, Gustavo Andrada; SEFFNER, Fernando. Futebol, gênero, masculinidade e homofobia: um jogo dentro do jogo. Espaço Plural, v. 29, p. 246-270, 2013.

BRANCO, Celso. Os papéis sociais do futebol brasileiro revelados pela música popular (1915-1990). In: SILVA, Francisco Carlos Teixeira da; SANTOS, Ricardo Pinto dos (Org.). Memória social dos esportes: futebol e política: a construção de uma identidade nacional. Rio de Janeiro: Mauad, 2006. p. 187-227.

CAILLOIS, Roger. Definição do jogo In: CAILLOIS, Roger. Os jogos e os homens. Lisboa: Cotovias, 1990. p. 23-30.

CECCHETTO, Fátima Regina. Violência e estilos de masculinidade. Rio de Janeiro: FGV Editora, 2004.

CONNELL, Robert W. Políticas da masculinidade. Educação \& Realidade, v. 20, n. 2, p. 185-206, jul./ dez. 1995.

COSTA, Felippe; RIZZATTI, Lucas; SEDA, Vicente. Pleno do STJD retira três pontos e elimina o Grêmio da Copa do Brasil. 26 set. 2014. Disponível em: <http://globoesporte.globo.com/futebol/ times/gremio/noticia/2014/09/pleno-do-stjd-retira-tres-pontos-e-elimina-o-gremio-da-copa-do-brasil. html>. Acesso em: 13 jan. 2015.

CREPALDI, Fabricio. Aranha desabafa e ironiza torcedora: "tentou chorar e não conseguiu". 18 set. 2014. Disponível em: <http://globoesporte.globo.com/futebol/times/santos/noticia/2014/09/vaiadoaranha-desabafa-e-diz-que-nao-ira-dar-desculpas-para-esse-povo.html>. Acesso em: 9 jan. 2015.

DAMO, Arlei Sander. 0 espetáculo das identidades e das alteridades: as lutas pelo reconhecimento no espectro do clubismo brasileiro. In: CAMPOS, Flavio de; ALFONSI, Daniela. (Org.). Futebol objeto das ciências humanas. São Paulo: Leya, 2014. p. 23-55.

DAMO, Arlei Sander. $O$ ethos capitalista e o espírito das copas. In: GASTALDO, Édison Luis; GUEDES, Simoni Lahud. (Org.). Nações em campo: Copa do Mundo e identidade nacional. Niterói: Intertexto, 2006. p. 39-72.

ELIAS, Norbert. Introdução. In: ELIAS, Norbert; DUNNING, Eric. A busca da excitação. Lisboa: Difel, 1992. p. 39-99.

ELIAS, Norbert. Sugestões para uma teoria de processos civilizadores. In: ELIAS, Norbert. 0 processo civilizador II: formação do estado e civilização. Rio de Janeiro: Zahar, 1993. p. 191-262.

EX-PRESIDENTE do Grêmio critica Aranha e minimiza ofensas: "É folclore." 2 set. 2014. Disponível em: <http://globoesporte.globo.com/futebol/times/gremio/noticia/2014/09/ex-presidente-do-gremiocritica-aranha-e-minimiza-ofensa-e-folclore.html>. Acesso em: 3 jan. 2015. 
GARRIGA ZUCAL, José. Nosotros nos peleamos: violência e identidade de uma hinchada de fútbol. Buenos Aires: Prometeo Libros, 2010.

GASTALDO, Edison. As relações jocosas futebolísticas: futebol, sociabilidade e conflito no Brasil. Mana, v. 16, p. 311-325, 2010.

GERAL reitera "suspensão" de cânticos, mas não vê racismo no termo macaco entoado pela torcida. 9 set. 2014. Disponível em: <http://zh.clicrbs.com.br/rs/esportes/gremio/noticia/2014/09/geral-reiterasuspensao-de-canticos-mas-nao-ve-racismo-no-termo-macaco-entoado-pela-torcida-4594378.html>. Acesso em: 27 out. 2015.

GRÊMIO defende punição a torcedores: "Não vamos compactuar com racismo". 28 ago. 2014a. Disponível em: <http://globoesporte.globo.com/futebol/times/gremio/noticia/2014/08/gremio-defendepunicao-torcedores-nao-vamos-compactuar-com-racismo.html>. Acesso em: 31 dez. 2014.

GRÊMIO divulga nota de repúdio a ato de racismo e se solidariza a Aranha: goleiro do Santos foi ofendido por torcedores que estavam atrás das traves. 28 ago. 2014b. Disponível em: <http:/l globoesporte.globo.com/futebol/times/gremio/noticia/2014/08/gremio-se-solidariza-aranha-e-reiteraque-tomara-medidas-apos-racismo.html >. Acesso em: 30 dez. 2014.

GRÊMIO entra com faixa contra racismo e mensagens se espalham pela torcida: jogadores e gremistas na Arena se mobilizam antes de jogo com Bahia após episódio de injúrias raciais contra o goleiro Aranha, na última quinta-feira, pela Copa do Brasil. 31 ago. 2014c. Disponível em: <http:// globoesporte.globo.com/futebol/times/gremio/noticia/2014/08/gremio-entra-com-faixa-contra-racismoe-mensagens-se-espalham-pela-torcida.html>. Acesso em: 3 jan. 2015.

GRÊMIO revive polêmica após 5 meses e mira evitar imagem de "clube racista". 29 ago. 2014d. Disponível em: <http://globoesporte.globo.com/futebol/times/gremio/noticia/2014/08/gremio-revivepolemica-apos-5-meses-e-mira-evitar-imagem-de-clube-racista.html>. Acesso em: 30 dez. 2014.

GREMISTAS criam movimento para tirar palavra 'macaco' de cantos na Arena. 11 mar. 2014. Disponível em: <http://globoesporte.globo.com/rs/noticia/2014/03/torcedores-criam-movimento-paratirar-palavra-macaco-de-cantos-na-arena.html>. Acesso em: 30 dez. 2014.

HELAL, Ronaldo. Jogo Bonito versus Fútbol Criollo: imprensa e "olhar" argentino sobre nosso futebol. In: GASTALDO, Édison Luis; GUEDES, Simoni Lahud. (Org.). Nações em campo: Copa do Mundo e identidade nacional. Niterói: Intertexto, 2006. p. 165-195.

HOLLANDA, Bernardo Borges Buarque de. O fim do Estádio-Nação? notas sobre a construção e a remodelagem do Maracanã para a Copa de 2014. In: CAMPOS, Flavio de; ALFONSI, Daniela. (Org.). Futebol objeto das ciências humanas. São Paulo: Leya, 2014. p. 321-346.

HUIZINGA, Johan. Natureza e significado do jogo como fenômeno cultural. In: HUIZINGA, Johan. Homo ludens. São Paulo: Perspectiva, 1993. p. 3-33.

KOFF vê cantos de "macaco" como ato proposital: "Que torcedor é esse?" 31 ago. 2014. Disponível em: <http://globoesporte.globo.com/futebol/times/gremio/noticia/2014/08/koff-ve-cantos-de-macacocomo-ato-proposital-que-torcedor-e-esse.html>. Acesso em: 2 jan. 2015.

MARQUES, José Carlos. A crônica de esportes no Brasil: algumas reflexões. In: CAMPOS, Flavio de; ALFONSI, Daniela. (Org.). Futebol objeto das ciências humanas. São Paulo: Leya, 2014. p. 185-205.

MENEZES, Paula. Aranha esfria vaias com defesas e ataca nos microfones: "é triste." 19 set. 2014. Disponível em: <http://globoesporte.globo.com/rs/noticia/2014/09/jogou-em-todas-aranha-esfriavaias-com-defesas-e-ataca-nos-microfones.html>. Acesso em: 9 jan. 2015.

MOMBACH, Hiltor. Aranha: "veado" é agravante. 20 set. 2014. Disponível em: <http://www. correiodopovo.com.br/blogs/hiltormombach/?p=34415>. Acesso em: 27 out. 2015. 
MOREIRA, Verónica. Cuerpos en la trama de la política: saberes, habilidades y capitales que consagran a los hinchas. In: BRANZ, Juan; GARRIGA ZUCAL, José; MOREIRA, Verónica (Comp.). Deporte y ciencias sociales: claves para pensar las sociedades contemporáneas. La Plata: EDULP, 2013. p. 201-231.

PEREIRA, Leonardo Affonso de Miranda. Identidades em jogo: brasileiros e argentinos nos campos de futebol. In: CAMPOS, Flavio de; ALFONSI, Daniela. (Org.). Futebol objeto das ciências humanas. São Paulo: Leya, 2014. p. 71-113.

PRESIDENTE da Fifa elogia decisão do STJD que exclui Grêmio da Copa do Brasil. 4 set. 2014. Disponível em: <http://zh.clicrbs.com.br/rs/esportes/gremio/noticia/2014/09/presidente-da-fifa-elogiadecisao-do-stjd-que-exclui-gremio-da-copa-do-brasil-4590664.html>. Acesso em: 4 jan. 2015.

REIS, Heloísa Helena Baldy dos. Espetáculo futebolístico e violência: uma complexa relação. In: DAOLIO, Jocimar (Org.). Futebol, cultura e sociedade. Campinas: Autores Associados, 2005. p. 105130.

RIBEIRO, Luiz. Futebol e globalização. Jundiaí/SP: Fontoura, 2007.

SEFFNER, Fernando. Masculinidade bissexual e violência estrutural: tentativas de compreensão, modalidades de intervenção. In: UZIEL, Anna Paula; RIOS, Luis Felipe; PARKER, Richard G. (Org.). Construções da sexualidade: gênero, identidade e comportamento em tempos de AIDS. Rio de Janeiro: Pallas, 2004. p. 85-104.

VENTURELLI, Diogo; HAMMES, Tomás. Vaias, ironias e alta tensão: a visão da torcida no retorno de Aranha à Arena. 19 set. 2014. Disponível em: <http://globoesporte.globo.com/futebol/times/ gremio/noticia/2014/09/vaias-ironias-e-alta-tensao-visao-da-torcida-no-retorno-de-aranha-arena.html>. Acesso em: 8 jan. 2015.

VICE-PRESIDENTE do Grêmio faz críticas a Aranha: "uma grande encenação". 2 set. 2014. Disponível em: <http://globoesporte.globo.com/futebol/times/gremio/noticia/2014/09/vice-presidentedo-gremio-faz-criticas-aranha-uma-grande-encenacao.html>. Acesso em: 4 jan. 2015. 
